\title{
Characterization of Triphenylamino-Based Polymethine Dyes
}

\author{
Saleem Ullah, ${ }^{1}$ Irshad Ahmad, ${ }^{2}$ Yatimah Alias, ${ }^{3}$ \\ Ismail Yusoff, ${ }^{4}$ and Muhammad Aqeel Ashraf ${ }^{3,4}$ \\ ${ }^{1}$ Department of Chemistry, University of Jyväskylä, FI-40014 Jyväskylä, Finland \\ ${ }^{2}$ Chemical Resource Laboratory, Bio-Resources Division, Tokyo Institute of Technology, 4259 Nagatsuta-cho, Midori-ku, \\ Yokohama, 226-8503, Japan \\ ${ }^{3}$ Department of Chemistry, University of Malaya, 50603 Kuala Lumpur, Malaysia \\ ${ }^{4}$ Department of Geology, University of Malaya, 50603 Kuala Lumpur, Malaysia
}

Correspondence should be addressed to Muhammad Aqeel Ashraf; aqeelashraf@um.edu.my

Received 6 December 2012; Revised 29 March 2013; Accepted 14 April 2013

Academic Editor: Alexander Tatarinov

Copyright (C) 2013 Saleem Ullah et al. This is an open access article distributed under the Creative Commons Attribution License, which permits unrestricted use, distribution, and reproduction in any medium, provided the original work is properly cited.

In this high-technology application, age functional dyes especially polymethine dyes have captured much attention of the researchers due to their immense potential for high-tech uses. Polymethine dyes show promising absorption spectra in the visible range, which can be easily exploited for the use of written text copying, photographic imaging, or photothermographic recording materials. Keeping this in mind, our research is composed of an investigation of two triphenylamino-based polymethine dyes, a known polymethine dye 3 and a new one polymethine dye 5, which have been synthesized by the reaction of 4-(diphenylamino) benzaldehyde 2 and 4,4' -(phenylazanediyl) dibenzaldehyde 4 with $4,4^{\prime}$-vinylidene-bis(N, N-dimethylaniline) 1 . Based on bisdimethylaminophenylethylene moiety, the new polymethine dye showed more high absorption spectra in the range of $600-$ $700 \mathrm{~nm}$ than that of the known polymethine dye based on bis-dimethylaminophenylethylene moiety. Their maximum spectra were exhibited at $637 \mathrm{~nm}$ and $653 \mathrm{~nm}$, respectively. Their leuco-converted reversible colored forms were also investigated.

\section{Introduction}

Any of a class of dyes (as cyanines or merocyanines) characterized by a resonance structure containing a conjugated chain of carbon atoms, that is, at least in part an open chain (as in $-\mathrm{CH}(=\mathrm{CH}-\mathrm{CH})_{n}=$ ) attached to two polar atoms (as two amino nitrogen atoms either one of which is considered to be positively charged), are called polymethine dyes (PDs). PDs have been studied for more than a century; however, they continue to be actively investigated due to their multifunctional chemical, biological, and optical applications [13]. The most essential advantages of PDs are connected with their intense (with molar absorbance up to $3 \times 10^{5} \mathrm{M}^{-1} \mathrm{~cm}^{-1}$ ) and tunable absorption bands in the visible and near infrared (NIR) regions, which is important for the development of organic materials [4-7]. The electronic properties of these dyes can be modified by changing the conjugation chain length or by adding specific terminal groups of electron acceptor (A) or electron donor (D) nature.
The absorption spectra of polymethine dyes arise from the electronic transitions involving the $\pi$ electrons along the polymethine chain. The structure of one of the dyes studies is shown in Figure 1. The $\pi$ electrons are delocalized between the two nitrogen atoms of the chain.

The cation has two major "resonance" forms between structures A and B shown in Figure 1. Quantum mechanically, this means that the wave function for the molecule has essentially equal contributions from each state. Thus all the bonds along this chain can be considered equivalent, with bond order $3 / 2$ (similar to the $\mathrm{C}-\mathrm{C}$ bonds in benzene). Each carbon atom in the chain and each nitrogen at the terminus are bonded to three other atoms through $\sigma$ bonding, which leaves one valence electron per carbon that may be involved in $\pi$ bonding. In addition, the three remaining valence electrons on the two nitrogen atoms (why is it three?) contribute to the $\pi$ system. The free electron model assumes that the $\pi$ electrons are subject to a constant potential as they move along the polymethine chain as indicated 


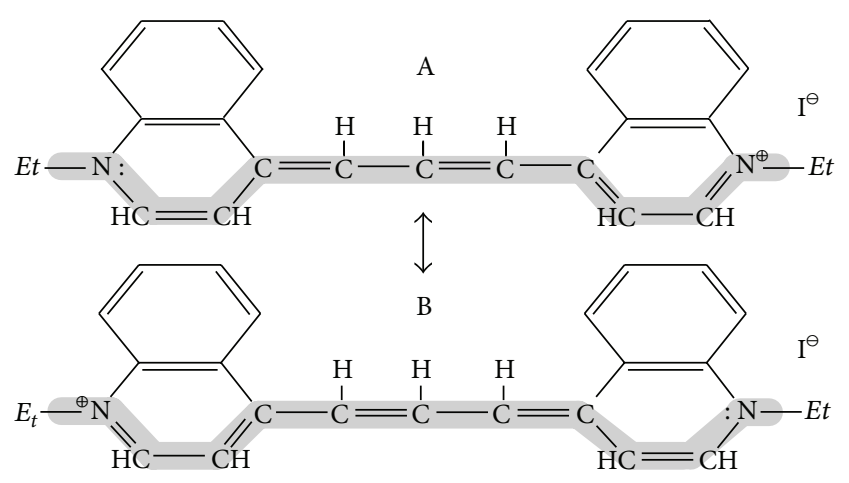

FIgURE 1: Two resonance structures of $1,1^{\prime}$-diethyl- $4,4^{\prime}$-carbocyanine iodide. The $\pi$-electron system of interest is highlighted.

in Figure 1. Furthermore, it is assumed that the potential increases very sharply in the region of the nitrogen atom and that the electrons behave as if they were confined to a "onedimensional box." Finally, we assume that electron-electron repulsion is negligible. The quantum mechanical solution for this system constrains the electron energies to the following values:

$$
E_{n}=\frac{n^{2} h^{2}}{\delta m L^{2}}, \quad n=1,2,3,
$$

where $h$ is Planck's constant, $m$ is the electron mass, and $L$ is the box length. Equation (1) gives the available electronic energies available to the $\pi$ electrons. The Pauli exclusion principle limits the number of electrons in any given energy level to two (corresponding to opposite spins: +12 , -12 ). If $N$ is the number of $\pi$ electrons in the conjugated chain, then for the ground state, each of the $N / 2$ levels contains two electrons and the remaining levels remain empty. Figure 1 shows that there are twelve electrons available (one from each carbon plus 3 from the two nitrogens) for the $1,1^{\prime}$-diethyl$4,4^{\prime}$-carbocyanine iodide dye.

Figure 2 shows the population of the energy levels of the $\pi$ system as estimated by the free electron model. The long wavelength absorbance maximum is assumed to be due to the $n=6$ to $n=7$ electronic transition. The photon energy is equal to the energy difference between levels $E_{6}$ and $E_{7}$ :

$$
h v=\frac{h c}{\lambda}=E_{7}-E_{6}=(49-36) \frac{h^{2}}{\delta m L^{2}}=\frac{13 h^{2}}{\delta m L^{2}} \text {. }
$$

We can calculate this energy level difference by using the free electron model providing that we can estimate the value of $L$. Let us denote the number of carbon atoms in a polymethine chain by $p$; then $N=p+3$ is the number of electrons in the box. Kuhnl assumed that $L$ was the length of the chain between nitrogen atoms plus one bond distance on each side; therefore $L$ can be found by

$$
L=(p+3) \rho,
$$

where $\rho$ is the bond length between atoms along the chain. A reasonable value for $\rho$ is $139 \mathrm{pm}$, which is the bond length
$E_{8}$
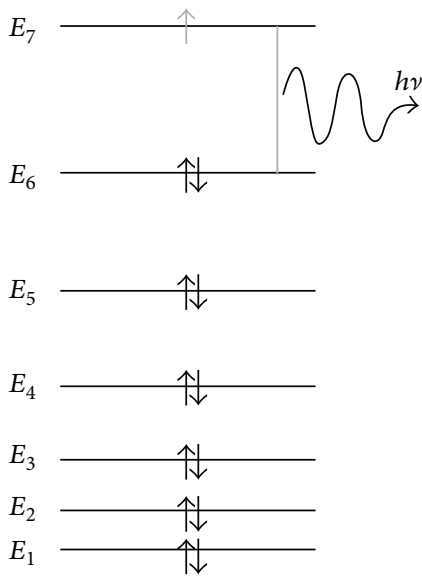

Figure 2: Population of the energy levels of the $\pi$ system.

in benzene. If there are easily polarizable groups at the ends of the chain (such as benzene rings), the potential energy of the $\pi$ electrons in the chain does not rise so sharply at the ends. In effect, this lengthens the path $L$ since the electrons can penetrate into the potential wall. Therefore we can write

$$
L=(p+3+\alpha) \rho,
$$

where $\alpha$ represents the penetration distance and should lie between 0 and 1 . The empirical parameter $\alpha$ should be constant for a series of dyes of a given type. When the procedure is done correctly, the calculation of $L$ and $\lambda$ (with $\alpha=0$ ) gives a wavelength of $707 \mathrm{~nm}$ for the dye shown in Figure 1.

Currently, the demand for dyes application for high technology is increasing, for example, novel demand for the use of written text copying or photographic imaging and photothermographic recording materials, which all have captivated the minds of researchers to the stirring developments in dye chemistry and dyes applications [8-14]. However, for conventional application, the use of polymethine dyes is limited to the dyeing and colorations for traditional textiles like wool, silk, leather, and polyacrylonitrile fibers $[8,9]$. In this background, competent research about the synthesis and characterization of new methine compounds in comparison to the preexisting known methine dyes has become increasingly important for many color formation systems and their high-quality chromic property application due to increased demand.

One of the best properties of polymethine dyes is their color producing reaction through the making of leuco form. The term "leuco" representing white was originally applied to the reduced forms of vat dyes in alkaline media which were often colorless. More recently, the usage has been extended to include the (usually) colorless form of a dye, which can be produced by a nonreductive process. Commonly, the alkaline soluble leuco vat dyes have been, of course, 
extremely important in textile dyeing. However, in all cases, the important feature of the reaction involved is the color change. The applications of leuco dyes are far more diverse than the conventional concept, and the term "leuco" has become standard to describe the reversibly reduced form of any class of dye which can be exploited in some way, especially in new high-technology applications [13-15].

The color forming precursors, leuco dyes, have received less attention in the literature. The largest portion of the annual production of the polymethine class of leuco dyes is consumed in the manufacturing of various copying papers. In this context, to provide a reversible coloroccurring system, two types of polymethine dyes, which are based on bis-dimethylaminophenylethylene moiety [10], were synthesized using 4-diphenylaminobenzaldehyde and 4,4-(phenylazanediyl) dibenzaldehyde as given in Scheme 1. The leuco form of these methine dyes was also prepared by the treatment using methanol with $\mathrm{NaOH}$. The absorption properties of two polymethine dyes were determined by using a UV spectrophotometer. Thus, the work herein comprises an investigation of the characterization of the triphenylaminobased new polymethine dye and a known polymethine dye.

\section{Methods}

2.1. Materials and Synthesis. All solvents and chemicals used in this work were of analytical grade and were used without further purification. Triphenylamine and 4,4'-vinylidenebis(N,N-dimethylaniline) were purchased from Aldrich. DMF was purchased from Samchun. Acetic anhydride was purchased from Duksan Pharmaceutical Co. Ltd. The synthetic pathway of the two dyes is shown in Scheme 1.

2.1.1. Dye (2) and Dye (4). The starting materials 4-(diphenylamino) benzaldehyde (dye2) and $4,4^{\prime}$-(phenylazanediyl) dibenzaldehyde (dye4) were prepared by adopting literature procedures [15-17].

2.1.2. Dye (3). $4,4^{\prime}$-Vinylidene-bis(N,N-dimethylaniline) 1 $(0.62 \mathrm{mmol}, 0.166 \mathrm{~g})$ and 4 -(diphenylamino) benzaldehyde 2 $(0.153 \mathrm{~g})$ were added into a solution of $5 \mathrm{~mL}$ acetic anhydride [18]. A mixture of perchloric acid $(0.31 \mathrm{mmol}, 0.030 \mathrm{~g})$ and acetic anhydride $(5 \mathrm{~mL})$ was added to the prepared solution. The solution was refluxed for $2 \mathrm{hrs}$. The mixture was then cooled at room temperature and poured into excessive ethyl ether. And then the precipitate was filtered and the solid product 3 was obtained.

2.1.3. Dye (5). 4,4'-Vinylidene-bis(N,N-dimethylaniline) 1 (1.88 mmol, $0.5 \mathrm{~g})$ and $4,4^{\prime}$-(Phenylazanediyl) dibenzaldehyde $4(0.25 \mathrm{~g})$ were added to a solution of $10 \mathrm{~mL}$ acetic anhydride. Mixture of perchloric acid $(0.056 \mathrm{~mL})$ and acetic anhydride $10 \mathrm{~mL}$ was then added to the solution. The solution was refluxed for $4 \mathrm{hrs}$. The mixture was cooled to room temperature and poured into excessive ethyl ether. And then the precipitate was filtered and the solid product 5 was obtained.

2.2. Instrument. The spectroscopic properties for the original and the leuco form were determined by using a UV spectrophotometer (Agilent Technology, USA) and elemental analysis by using an Automatic Elemental Analyzer by Thermo Fisher Scientific (Flash EA 112 series). Analytical data agreed with the proposed structures.

2.2.1. Dye (2) Yield. 67\% (2.02 g); 1HNMR ( $400 \mathrm{MHz}$, CDCL3): $\delta 7.06(\mathrm{~d}, 2 \mathrm{H}) . \delta 7.19-7.25(\mathrm{~m}, 6 \mathrm{H}), \delta 7.38(\mathrm{t}, 4 \mathrm{H}), \delta 7.72$ $(\mathrm{d}, 2 \mathrm{H}), \delta 9.85(\mathrm{~s}, 1 \mathrm{H})$.

2.2.2. Dye (4) Yield. 47.21\% (1.41g); 1HNMR (400 MHz, CDCL3); $\delta 7.16-7.17(\mathrm{t}, 5 \mathrm{H}), \delta 7.76-7.79(\mathrm{~m}, 4 \mathrm{H}), \delta 7.24-7.28$ $(\mathrm{m}, 2 \mathrm{H}), \delta 7.38-7.42(\mathrm{~m}, 2 \mathrm{H}), \delta 9.89(\mathrm{~s}, 2 \mathrm{H})$.

2.2.3. Dye (3) Yield. $81.57 \%$ (0.2386 g); elemental analysis calculated for $\mathrm{C} 37 \mathrm{H} 36 \mathrm{ClN} 3 \mathrm{O} 4: \mathrm{C}, 71.43 ; \mathrm{H}, 5.83 ; \mathrm{N} 6.75$, found: C, 72.69; H, 6.13; N, $6.55 \lambda \max$ (dichloromethane) $637 \mathrm{~nm}$.

2.2.4. Dye (5) Yield. $61 \% \quad(0.4026 \mathrm{~g})$; calculated for C56H59ClN5 ${ }^{+2} \mathrm{O} 4$ : C74.59; H, 6.60; N, 7.77, found: C, 71.37; H, 6.77; N, $10 \lambda \max$ (dichloromethane) $653 \mathrm{~nm}$.

\section{Results and Discussion}

3.1. UV Absorption Spectra. Figures 3 and 4 show absorption spectra of these prepared methine dyes in dichloromethane. Both polymethine dye compounds based on bis-dimethylaminophenylethylene moiety showed distinct absorption spectra in the range of $600-700 \mathrm{~nm}$, and their maximum absorption peaks were exhibited at $637 \mathrm{~nm}$ and $653 \mathrm{~nm}$, respectively.

The increase in absorption of the spectra of Dye 5 is due to the extension in polymethine chain and an increase in conjugation which gives a good platform for intramolecular charge transfer $[19,20]$. In addition, the leuco forms of these dyes were prepared by the treatment using methanol with $\mathrm{NaOH}$. The absorption spectra for the converted leuco form of the methine dyes are also shown in Figures 3 and 4 . In the general area of imaging and copying, leuco dyes have a major part to play and affect the subject matter of this investigation. Thus, the leuco forms in Figures 1 and 2 shows the colorless properties of the methine dyes compared to the original spectra, and their corresponding characteristics could be considered as leuco moieties. This reversible color formation of an intense absorption band in the visible region (600$700 \mathrm{~nm}$ ) is of importance from the viewpoint of functional color-occurring systems. It is also an interesting concept that the prepared colorless or nearly colorless compounds react with acid to provide extension of the conjugated double-bond system, enabling color formation [21]. In this context, the leuco form caused by the addition of acid can be considered a reversible color formation system of these polymethine dyes.

\section{Conclusion}

The absorption spectra of both polymethine dyes and their leuco form were studied. It was shown that both polymethine dyes show completely different spectroscopic parameters. It 


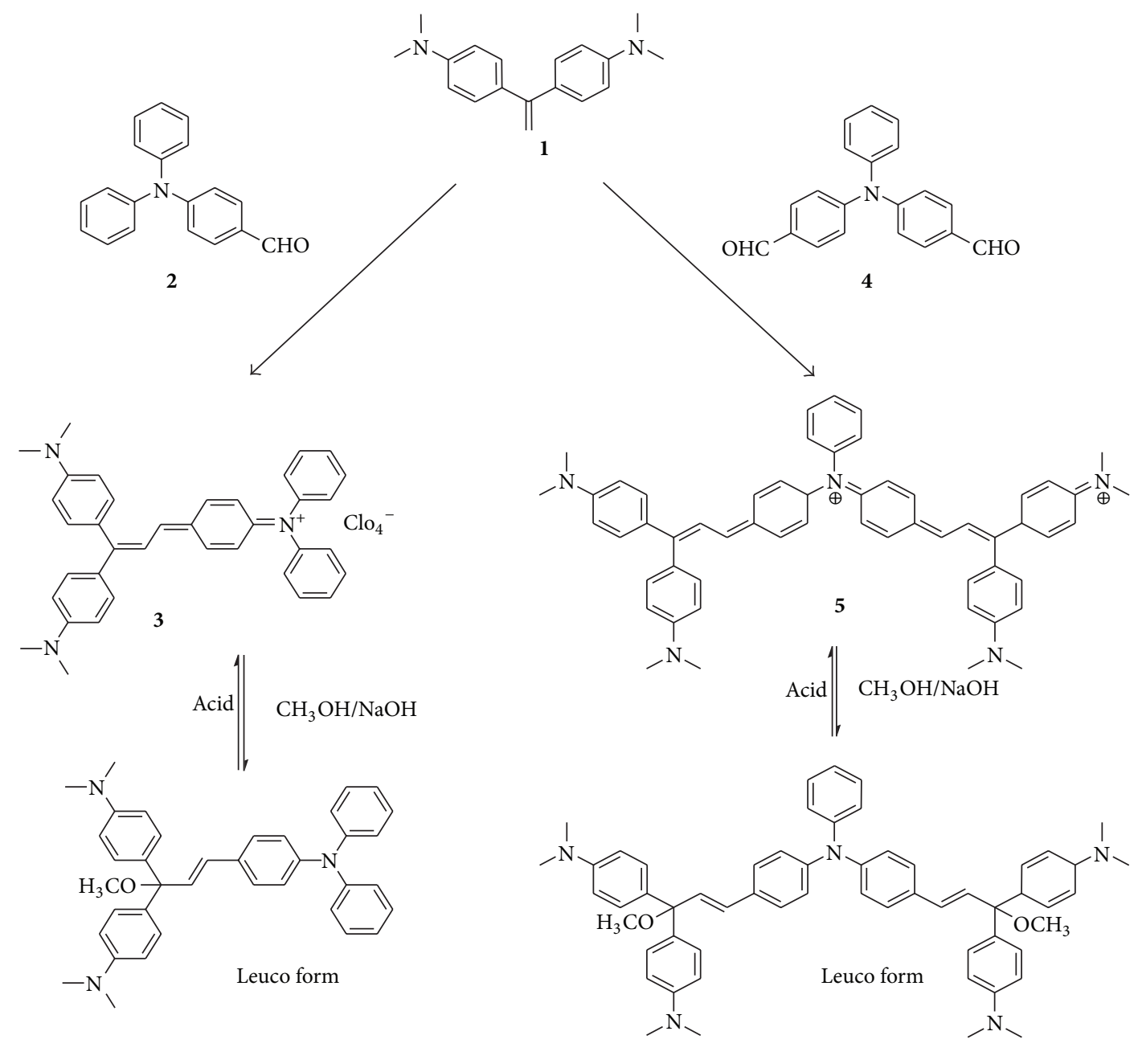

SCHEME 1

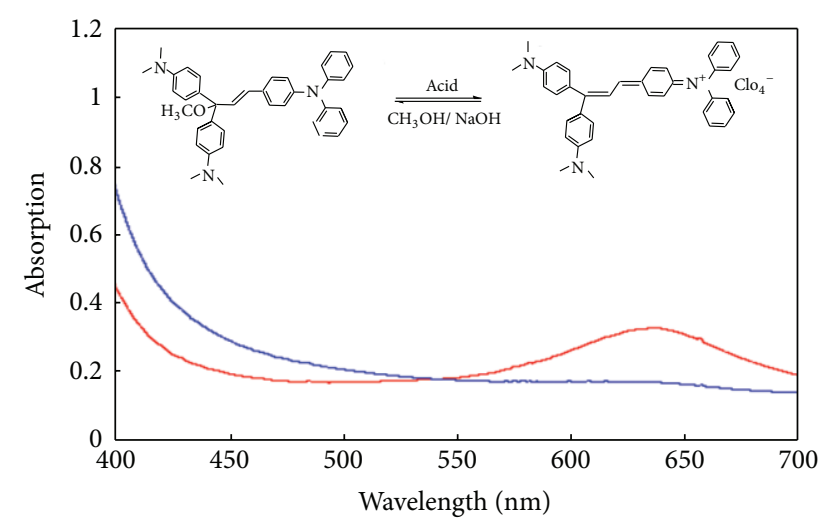

FIgURE 3: Absorption spectra of methane dye 3 and its leuco form in dichloromethane.

was revealed that the new polymethine dye 5 shows broad absorption spectra in comparison to the known dye 3 which can be easily exploited for the use of written text copying, photographic imaging, or photothermographic recording materials.

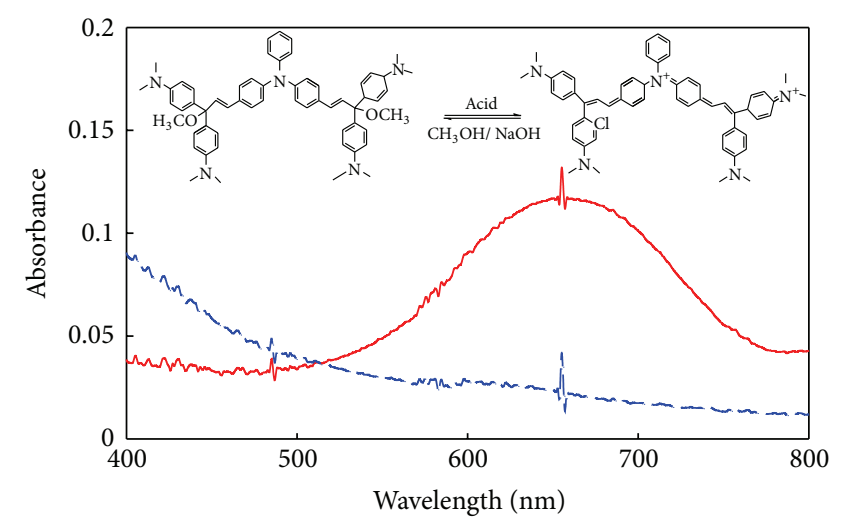

FIGURE 4: Absorption spectra of methine dye 5 and its leuco form in dichloromethane.

\section{Acknowledgments}

This study was financially supported by Grants UMRG04209AFR, PV112/2012A from the "IPPP University of Malaya, Malaysia and Brain Korea 21 (BK21) project. The experiment 
was done at the Hydrogeology Laboratory, Department of Geology, University of Malaya and color and colorant laboratory, Department of Advanced organic Materials and Textile System Engineering, Chungnam National University, South Korea. The authors wish to thank all the grant providers and also their graduate students and colleagues who supported this research work.

\section{References}

[1] A. Mishra, R. K. Behera, P. K. Behera, B. K. Mishra, and G. B. Behera, "Cyanines during the 1990s: a review," Chemical Reviews, vol. 100, no. 6, pp. 1973-2012, 2000.

[2] F. Meyers, S. R. Marder, and J. W. Perry, Introduction to the Nonlinear Optical Properties of Organic Materials, Wiley-VCH, New York, NY, USA, 1998.

[3] J. Fabian, H. Nakazumi, and M. Matsuoka, "Near-infrared absorbing dyes," Chemical Reviews, vol. 92, no. 6, pp. 1197-1226, 1992.

[4] N. Peyghambarian, L. Dalton, A. Jen et al., "Technological advances brighten horizons for organic nonlinear optics," Laser Focus World, vol. 42, no. 8, pp. 85-94, 2006.

[5] T. D. Iordanov, J. L. Davis, A. E. Masunov et al., "Symmetry breaking in cationic polymethine dyes, part 1: ground state potential energy surfaces and solvent effects on electronic spectra of streptocyanines," International Journal of Quantum Chemistry, vol. 109, no. 15, pp. 3592-3601, 2009.

[6] J. M. Hales, J. Matichak, S. Barlow et al., "Design of polymethine dyes with large third-order optical nonlinearities and loss figures of merit," Science, vol. 327, no. 5972, pp. 1485-1488, 2010.

[7] O. V. Przhonska, S. Webster, L. A. Padilha et al., Advanced Fluorescence Reporters in Chemistry and Biology I: Fundamentals and Molecular Design, Springer Series in Fluorescence, Springer, Berlin, Germany, 2010.

[8] H. Zollinger, Color Chemistry, Wiley-VCH, Weinheim, Germany, 2003.

[9] D. R. Waring and G. Hallas, The Chemistry and Application of Dyes, Plenum Press, New York, NY, USA, 1990.

[10] H. K. Sung, Functional Dyes, Elsevier Science and Technology, 2006.

[11] M. Matsuoka, Infrared Absorbing Dyes, Plenum Press, New York, NY, USA, 1990.

[12] P. Gregory, High-Technology Applications of Organic Colorants, Plenum Press, New York, NY, USA, 1991.

[13] L. Chen, Y. Cui, X. Mei et al., "Synthesis and characterization of triphenylamino-substituted chromophores for nonlinear optical applications," Dyes and Pigments, vol. 72, no. 3, pp. 293-298, 2007.

[14] Y. A. Son, B. S. Kim, M. S. Choi, and S. H. Kim, "Polymethine dye synthesis and its leuco property investigation," Molecular Crystals and Liquid Crystals, vol. 472, no. 1, pp. 225-230, 2007.

[15] Y. Nakano, T. Yagyu, T. Hirayama et al., "Synthesis and intramolecular magnetic interaction of triphenylamine derivatives with nitronyl nitroxide radicals," Polyhedron, vol. 24, no. 16-17, pp. 2141-2147, 2005.

[16] F. Meng, C. Liu, J. Hua et al., "Novel linear and tri-branched copolymers based on triphenylamine for non-doping emitting materials," European Polymer Journal, vol. 39, no. 7, pp. 13251331, 2003.
[17] G. Lai, X. R. Bu, J. Santos, and E. A. Mintz, "Reinvestigation of the Vilsmeier-Haack formylation of triphenylamine," Synlett, vol. 1997, no. 11, pp. 1275-1276, 1997.

[18] Y. A. Son and S. H. Kim, "Synthesis and properties of new polymethine dyes based on bis-dimethylaminophenylethylene moiety," Dyes and Pigments, vol. 72, no. 3, pp. 403-405, 2007.

[19] G. G. Dyadyusha, A. A. Ishchenko, N. A. Derevyanko, M. A. Kudinova, and A. I. Tolmachev, Theoretical and Experimental Chemistry, Springer, New York, NY, USA, 2004.

[20] J. Seixas de Melo, A. P. Moura, and M. J. Melo, "Photophysical and spectroscopic studies of indigo derivatives in their keto and leuco forms," The Journal of Physical Chemistry A, vol. 108, no. 34, pp. 6975-6981, 2004.

[21] S. Chatterjee, P. D. Davis, P. Gottschalk et al., "Photochemistry of carbocyanine alkyltriphenylborate salts: intra-ion-pair electron transfer and the chemistry of boranyl radicals," Journal of the American Chemical Society, vol. 112, no. 17, pp. 6329-6338, 1990. 

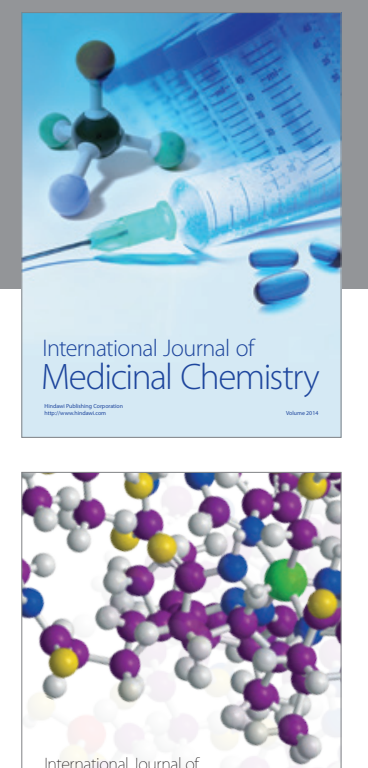

\section{Carbohydrate} Chemistry

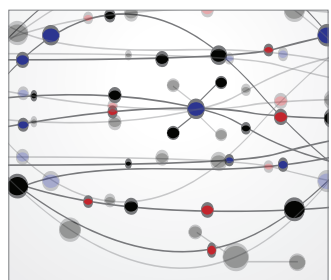

The Scientific World Journal
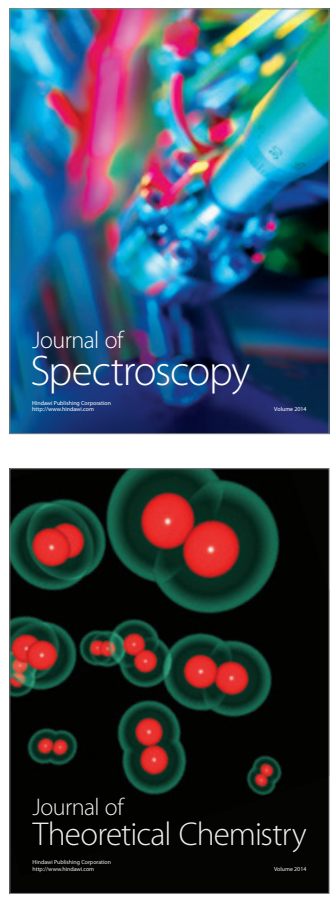
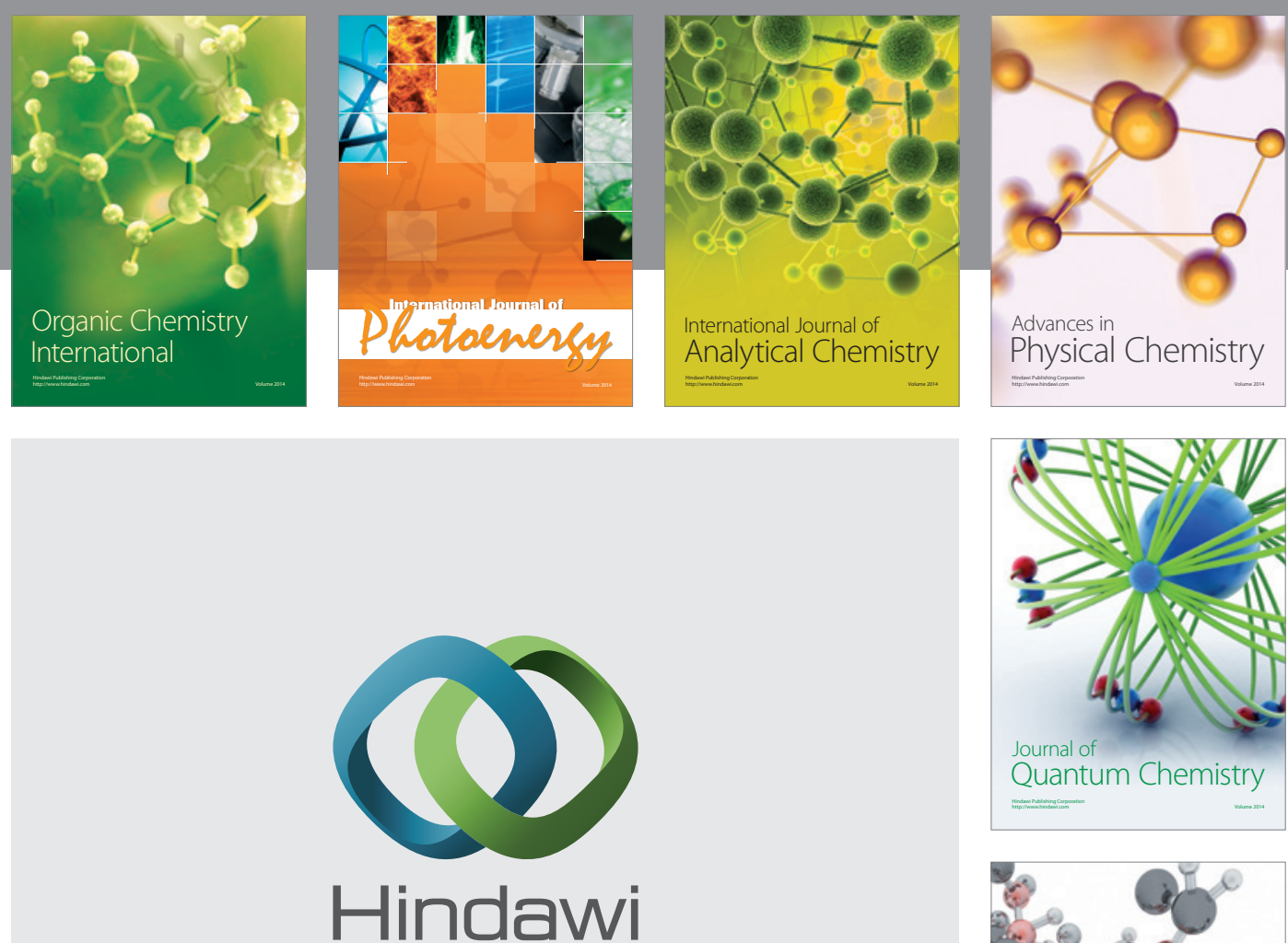

Submit your manuscripts at

http://www.hindawi.com

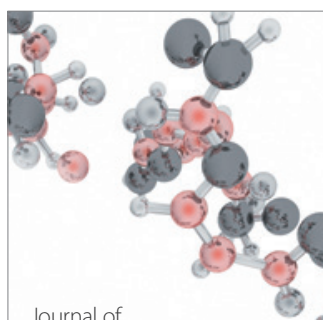

Analytical Methods

in Chemistry

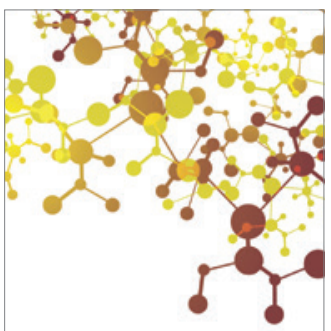

Journal of

Applied Chemistry

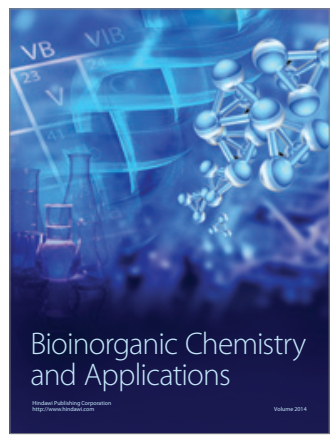

Inorganic Chemistry
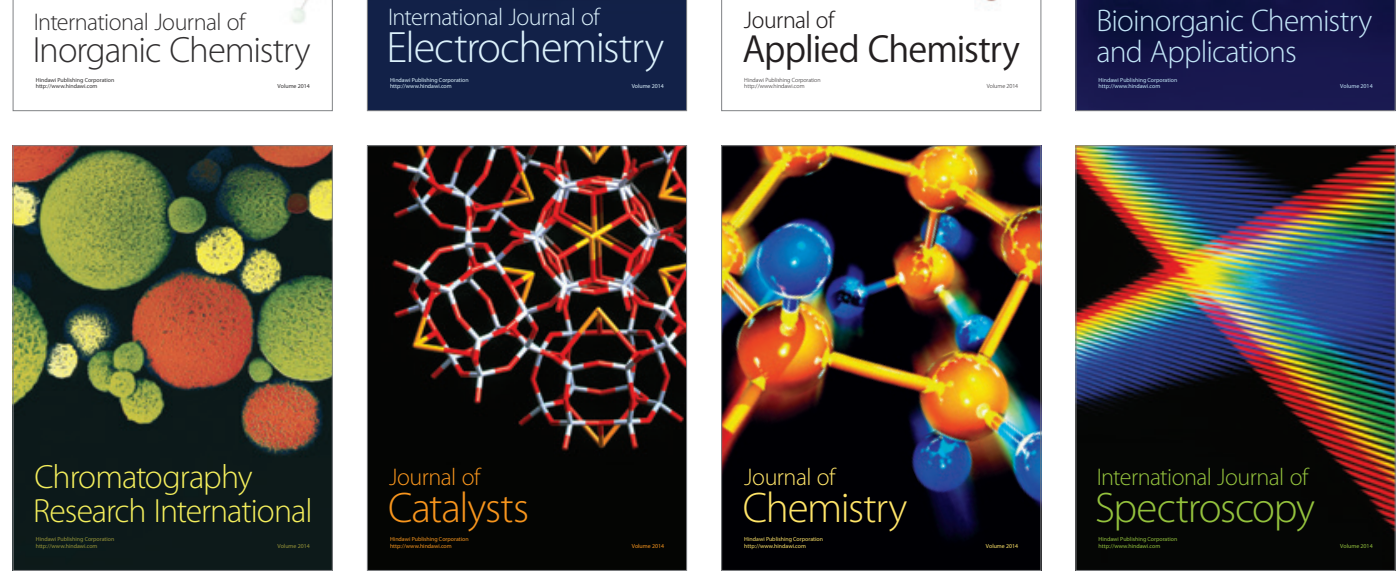